\title{
Involving Novice Users in Document-Driven System Requirements Analysis
}

\author{
Stefan Cronholm and Göran Goldkuhl \\ Linköping University, Linköping, Sweden
}

\author{
scr@ida.liu.se ggo@ida.liu.se
}

\begin{abstract}
This article proposes a document-driven approach to analysis of system requirements. The objective of this approach is to establish better ways of communicating with novice users. We have based our research on two principles: 'connecting to what is known' and 'shifting between abstractions and concretions.' The former principle means that existing familiar documents have been used as a starting point. The latter principle refers to relating the abstractions made in the system development process to something that is concrete to the user. Our document-driven approach was implemented in a case study discussed in the article. Our approach resulted in improved conditions for communication between users, in conceptual improvements, and in process improvements.
\end{abstract}

Keywords: Requirements Analysis, Information Systems Modeling, User participation, Communication Analysis, Conceptual Analysis.

\section{Introduction}

The research question we address in this paper reads: How should a requirements analysis be carried out when novice users are involved? When planning a project for developing an information system (IS), it is necessary to consider many issues, such as time limits, which project members should be participating and whether they are available, and if there is feasible support in terms of methodologies and computer support. The type of project and the experience of the project members have also to be considered. In other words, there is a need for characterising the project conditions.

Members of a development project can have different experiences. Due to high maturity of information technology (IT) in today's organizations, many users are likely to have significant experience with computer use and information systems development (ISD). However, there are still situations where novice users participate in ISD projects. This means that they have a lower degree of experience from interacting with computers and no experience from participating in dif-

Material published as part of this journal, either on-line or in print, is copyrighted by the publisher of the Informing Science Journal. Permission to make digital or paper copy of part or all of these works for personal or classroom use is granted without fee provided that the copies are not made or distributed for profit or commercial advantage AND that copies 1) bear this notice in full and 2) give the full citation on the first page. It is permissible to abstract these works so long as credit is given. To copy in all other cases or to republish or to post on a server or to redistribute to lists requires specific permission and payment of a fee. Contact Publisher@ijikm.org to request redistribution permission. ferent change or development projects. In this research we address the problems of involving novice users in ISD projects. We focus on the analysis phase and some recommendations for the design phase, rather than on a full development methodology (that has other phases such as design, construction, implementation, and maintenance). 
There are many competitive methodologies for analysing business processes and business information in order to develop ISes. Sometimes these methodologies also tell us why we should act in one way or another (e.g., Jayaratna, 1994). One of the most popular methodologies today is the object-oriented approach called Rational Unified Process (RUP) (e.g., Kruchten, 1999). What these methodologies do not tell us is how to perform ISD when project members are novices. Introna and Whitley (1997) argue that relying exclusively on methodologies can be risky. Further, they claim that methodologies cannot bring light to all characteristics of the situation that can be discovered. We think that these methodologies are too complex and abstract when an IS is being developed in close collaboration with future end-users that have no or little experience of using computers and participating in ISD projects.

Advocates of the participatory design approach have paid significant attention to the influence of users on the ISD process. They argued for a broad and genuine participation aiming at agreement between ISes and the organization of work (Hägerfors, 1994; Kensing, 2003; Kling, 1977; Mumford \& Henshall, 1983). Carlshamre (1994) posited that participatory design was more of a philosophy than a methodology. Although participatory design has included some techniques to facilitate requirements analysis, it lacked a procedural description of how and when to apply these techniques.

Vonk (1990) and Urquhart (1998) argued that there was a communication gap between the professional systems developers and the users. Vonk (1990) maintained that the main problem was a use of different languages. The author advocated a more extensive use of pictures in order to overcome this problem. Vonk (1990) preferred a prototyping approach that would bring more attention to the user interface than traditional ISD methodologies did. Many research efforts have been pursued in the area of user involvement and participatory design. But as Markus and Mao (2004) concluded, while "prior research has offered evidence in support of a link between participation and system success, ... much remains to be understood about how and why participation works" (p. 524). They suggested that research should be refocused toward the practices of IS developers when they facilitate user participation. It is crucial that developers and users work together, rather than just interact in design meetings. The authors add, and we concur, that "it is not the mere fact or quantity of participation that matters, but also the quality of participation" (p. 536).

The challenge of creating good communication between designers and novice users has led us to develop and use a document-driven approach in a participatory design spirit. The purpose of our research is, therefore, to develop and to apply a document-driven approach for system requirements analysis that involves novice users. In the following discussion, we will present this approach along with results of using it in a case study. The paper should, thus, be seen as a contribution to methods of increasing the participation of novice user in the activities of system requirements analysis.

Our document-driven approach to requirements analysis was developed in a case study based on action research (see Baskerville \& Myers, 2004; Baskerville \& Wood-Harper, 1996; Cunha \& Figueiredo, 2002; Gummesson, 1988; McKay \& Marshall, 2001). The case refers to an orgainsation providing home care for elderly people.

This introductory section is followed by a description of tools for novice user involvement. The next section describes our research approach and the following section describes a document analysis and document redesign in a work practice. Next, we will discuss findings and then draw conclusions. 


\section{Tools for Novice User Involvement}

Nielsen (1993) discusses novice and expert users and claims the importance of identifying the users' previous knowledge when designing IS (see Figure 1). Nielsen suggests that the most important issues for designing usable IS are the users' tasks and their individual characteristics and differences. Three main dimensions are utilised in order to describe users' previous knowledge: experience with the system, experience with computers in general, and experience with the task domain. In our case, the users can be characterized as novice users (see section 'Description of the Work Practice and the Development Project' for more details).

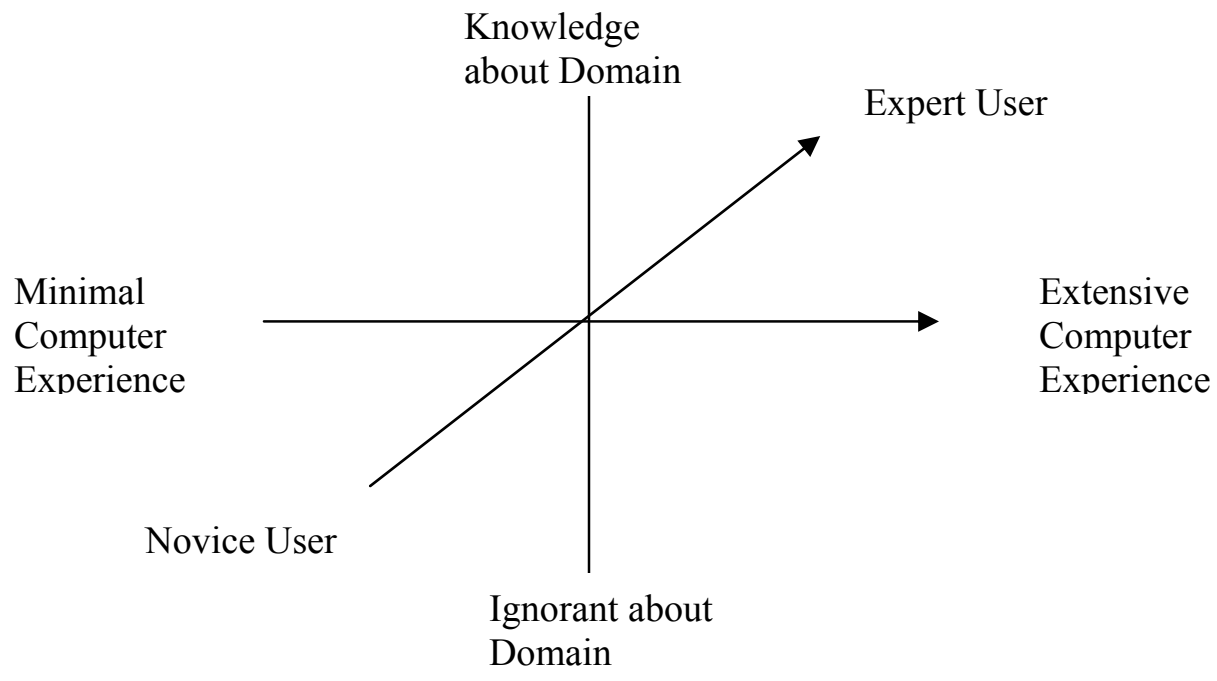

Figure 1: The three main dimensions on which user experience differs

(Nielsen, 1993)

In order to support involvement of novice users, we have based our approach on two fundamental pillars:

- Connect to what is known

- Shift between the abstract and the concrete.

Connect to what is known means to start with what is familiar in the work practice. It means to find suitable anchorages that simplify the analysis process for the users. These anchorages must be familiar and easily understood. Examples of what is familiar can be the work practice language and existing documents. Such phenomena have been used as means for understanding, reconstructing and developing the work practice. This pillar can be seen as a reaction against the Business Process Reengineering (BPR) argumentation about starting development with a "clean slate" (Hammer \& Champy, 1993). In order to create a radically new business process one should, according to classical BPR, disregard existing processes. We question if this is a proper approach when novice users participate in ISD. In order to involve novice users we hypothesize that one should use the familiar current work practices as a starting point (Goldkuhl \& Röstlinger, 2002; Greenbaum \& Kyng, 1991).

In order to analyze 'what is known' and to capture the communication in the work practice, it should be possible to collect existing documents as a starting point. To collect existing documents means to identify and understand when and where in the work practice these documents are used. The purpose of documents is often to transfer knowledge between personnel and to ensure that 
commitments between producers and clients are performed. The arguments for choosing existing documents as a starting point in this situation were:

- the work practice embraces many document types

- a majority of the concepts used should be represented in the documents

- the documents work either as a condition for or as a result of an action

- the concepts in the work practice documents are familiar to the users.

Documents are produced, used and changed. To create a document (or parts of it) is to be seen as performing a communicative act. An actor in the work practice not only represents something in a document but creates certain relationships (commitments, expectations, etc.) to other persons by creating the document. We follow speech act theory (Habermas, 1984; Searle, 1969) and its applications in the IS area (e.g., Goldkuhl \& Lyytinen, 1982; Winograd \& Flores, 1986). Documents have important characteristics that distinguish them from oral utterances. Documents have persistence. People can read them and save them and read them again. Documents can also be changed. A person can add something to an existing document or change something in it. This means that documents can be results of several communicative acts, which can also be performed by different people. Documents play important roles in a work practice when they are used as communication instruments for performing the work practice. Such documents represent important acts in the work practice and they are used to externalise work knowledge and constitute a collective external memory for the work practice. The documents are also carriers of the work language of the practice. Being representations of actions, knowledge and language in the work practice, documents are not only instruments for performing the work practice but also instruments for constituting the practice (Goldkuhl \& Röstlinger, 2002). Because of these fundamental characteristics, we believe that work practice documents are an important means of studying and understanding a work practice.

In order to perform and support the pillar 'connect to what is known' we have used communication analysis. Every researcher is concerned about how to ask 'good' questions. Inspired by Strauss and Corbin (1998) our inquiry consists of questions such as, why and how is this document used? What is the meaning of this concept? Why is this information represented in this document? For what purpose is this information used? What do you need in order to produce this information, and to whom do you communicate this information? The purpose of these questions was to learn about possibilities of improving the conditions for communication in the design process.

The focus on documents implies an interest in both current and future documents. Current documents may be paper documents if the work practice has not been computerized. Shifting to a computer-based work practice means a shift of media. Paper documents are changed to electronic ones. A focus on future documents can be made by the aid of prototyping.

We have also based our approach on the pillar 'shift between the abstract and the concrete'. The novice users were not experienced in working with abstractions like business models. Instead, we needed ways to be more concrete. When modelling IS one must always make abstractions. One way of confirming that a proper abstraction is made is to relate it to something concrete. Alterations between the abstract and the concrete help both the developers and users to understand the phenomena of interest. For developers, a concretion could confirm that the right abstraction is made. For novice users, a concretion simplifies the abstraction. Hence, one can say that a concretion validates the abstraction made. We think that alterations between different abstractions levels are especially important when developing IS that involves novice users. 
One way of supporting the 'shift between the abstract and the concrete' is to use prototyping or iterative design (Vonk, 1990). Being able to observe and study prototypes means that the users can relate themselves to something concrete (Carlshamre, 1994). We have chosen prototyping for two reasons. First, instead of using more abstract notations of ISD methodologies we refer to something more concrete. Second, using something more concrete means that the users should be able to criticise the evolving IS more easily. In this study we have used both low and high fidelity prototypes (see Löwgren, 1993; Monk, Wright, Haber, \& Davenport, 1993).

We see 'connect to what is known', 'shift between the abstract and concrete', 'collect existing documents', 'prototyping' and 'communication analysis' as tools for developing IS with participation of novice users. The relations between the tools (as kinds of work principles) should not be seen as sequential. Rather, these could be used in an alternating fashion. The tools 'connect to what is known' and 'shift between the abstract and concrete' should be seen as the basic pillars that answers the question 'what to do?' The tools 'collect existing documents', 'prototyping' and 'communication analysis' should be seen as tools that answer the question 'how it should be done?'

\section{Research Approach}

The research that has been carried out can be viewed as action research (Baskerville \& Myers, 2004; Baskerville \& Wood-Harper, 1996; Cunha \& Figueiredo, 2002; Gummesson, 1988; McKay $\&$ Marshall, 2001). Action research means to intervene in a process. When we started the project the research approach had not been selected yet. Our reason for not deciding on a research approach in advance was that we were facing a new situation that involved novice users. Rather, the research approach action research emerged in the course of the project. The reason for doing action research was that we considered it to be an appropriate methodology since we had both an action interest and a research interest. The action interest was to analyze and design an information system as a support to the elderly care practice. The research interest was to try and validate the idea of how to involve novice users in ISD. This means that we have both acted as researchers and as professional requirements analysts.

The model in Figure 2 describes our view of action research (Cronholm \& Goldkuhl, 2004). There are three interlinked practices: (a) the theoretical research practice (studying the idea of how to involve novice users), (2) the change practice/empirical research practice (carrying out a development project for testing the idea), and (3) the regular practice (managing the home care unit).

\begin{tabular}{|l|l|l|l|l|}
\hline $\begin{array}{l}\text { Theretical } \\
\text { research } \\
\text { practice }\end{array}$ & $\begin{array}{l}\text { research } \\
\text { interest }\end{array}$ & $\begin{array}{l}\text { Business } \\
\text { change } \\
\text { practice/the } \\
\text { empirical } \\
\text { research } \\
\text { practice }\end{array}$ & $\begin{array}{l}\text { change } \\
\text { request }\end{array}$ & $\begin{array}{l}\text { empirical } \\
\text { data }\end{array}$ \\
& $\begin{array}{l}\text { change } \\
\text { result }\end{array}$ & $\begin{array}{l}\text { Regular } \\
\text { business } \\
\text { practice }\end{array}$ \\
\end{tabular}

\section{Figure 2: Three interlinked practices \\ (Cronholm \& Goldkuhl, 2004)}

In this paper, the research part has been of primary interest since the aim was to develop knowledge. The research was carried out through reflection on the introduction of the suggested tools for the involved novice users. This means that the development project has served as a source for 
collecting empirical data. When the data had been collected, we conducted a data analysis (see below) together with an articulation of the different tools used. This data analysis included an evaluation of the tools and their application in the project. The work practice (the home care unit) has acted as a base for carrying out the project. It is important to note that there is a flow of data and results between the practices. A common criticism against participatory action research is that it lacks scientific rigor (Kemmis \& McTaggart, 2000). In order to reduce this criticism we have been careful about distinguishing between the role of researcher and of professional requirements analyst.

The research approach is based on the following process: 1) formulating an idea about how to involve novice users, 2) applying the idea and 3) evaluating the idea (see Figure 3).

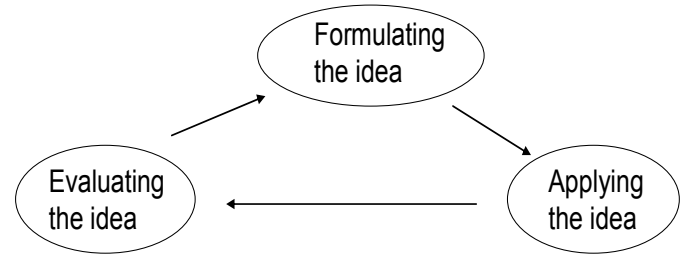

Figure 3: The Research Process

The project, which was carried out over approximately one year, had the explicit purpose of knowledge utilisation improvement and a particular focus on quality assurance. One can consider the project to be a work practice development with special emphasis on knowledge, quality and IT issues. Data gathering has been achieved by different qualitative research tools: 11 semistructured interviews with directors and nursing assistants, two observations of nursing assistants working with prototypes, the collection and analysis of several documents such as ordering services, journal information and week planning, and participation in development seminars. Many of the project's meetings were video-recorded which has given us the opportunity to look closely at what was actually said by different people during the requirements analysis. Closeness to the empirical phenomena was necessary in order to gain reliable data. As stated above, a participatory approach has been taken, including active cooperation with the staff at the home care unit.

The analysis of the data can be characterized as qualitative. According to Kvale (1989) and Strauss and Corbin (1998), qualitative approaches should be used for answering the questions of why, what and how. Kvale (1989) points pout that the aim of qualitative approaches is to achieve a deeper understanding of a phenomenon. Five categories have been used as tools in order to gather the data required. They are referred to as: 'what is known,' 'shift between the abstract and concrete,' 'collect existing documents as a starting point,' 'prototyping,' and 'communication analysis.' The second and last category emerged during the development process rather than being determined before the project. The research strategy implemented is a process model focusing on what happens in the user-developer interaction instead of a factor model focusing on contextual forces (Newman \& Robey, 1992).

\section{Work Practice and System Development Project}

The project was carried out in a home care unit for the elderly people (clients) in a medium-sized Swedish municipality. The personnel of the unit consisted of 50 nursing assistants responsible for the daily work with the clients and two directors. The major function of the home care unit was to help senior citizens by assisting them in tasks, such as keeping personal hygiene, minor medical interventions, cleaning and laundry chores, shopping, etc. 
One main objective for the studied home care service was individualisation. Each client had individual needs and, therefore, the tasks performed for different clients varied. Clients' needs could also change over time. The role of the nursing assistants was to support the clients to live their lives in their own desired ways. This goal implied a great need for knowledge. The nursing assistants had to have a good picture of clients' historical and current social life, medical situation, habits and needs. There was a need for transferring this knowledge to all members of the home care team since different assistants could be responsible for a particular client.

The aim of the system development project was to establish support for providing maximum individualisation of the clients' needs. The project focused on how to facilitate communication and to support the transfer of client knowledge between the nursing assistants themselves - the users of the nascent IS. Two nursing assistants and two elderly care directors participated actively in the study.

One important pre-condition was that our system users had no previous experience of participating in systems development projects. This meant that we could not expect them to be trained in working with abstractions like business models (process models, data models). In addition, the users had no experience from working in development projects. This meant that we could not expect them to know how to work with abstractions like business models (process models, data models). In a word, these were novice user (Nielsen, 1993); see Figure 1 and the corresponding discussion above. The users had a very low degree of general computer experience (only a few computers were available, and these were mainly used by the managers). On the other hand, the users had a high degree of knowledge about the domain (most of the nursing assistants were employed for several years).

We agree with Nielsen's (1993) assumption that identifying users' previous knowledge is important for designing IS. One can argue that a lack of experience with electronic ISes can be compensated to by education and training. We acknowledge that there must be some IS training before using the IS in a real work situation. Still, the main design goal must be to develop IS according to previous knowledge of users.

\section{Document Analysis and Document Redesign in the Work Practice}

The purpose of this section is to present a brief description of how the development project was carried out with reference to the tools mentioned above (see Cronholm \& Goldkuhl, 2005) for a more detailed description). The description begins with an analysis of the current work practice situation followed by an analysis of the future situation, which is based on problems identified in the current situation.

\begin{tabular}{|l|l|l|l|}
\hline \multicolumn{2}{|l|}{} & Morning tasks \\
\hline $\begin{array}{l}\text { Apartment } \\
\text { Number }\end{array}$ & Time & Name & Task Description \\
\hline 1414 & 07.15 & Roy & Visiting the bathroom Monday - Wednesday -Friday \\
\hline 1406 & 07.30 & Fanny & Dressing, visiting the bathroom Tuesday - Thursday \\
\hline 203 & 07.30 & Douglas & Making the bed, medicine \\
\hline 108 & 07.30 & Elisabeth & Hygiene, dressing \\
\hline$\cdots$ & $\cdots$ & $\cdots$ & $\cdots$ \\
\hline
\end{tabular}

Figure 4: Morning tasks 
The document chosen to best illustrate this is labeled 'Morning tasks' (see Figure 4). The reason for choosing this document is that it is frequently used in the nursing assistants' daily work with their clients. The document consists of four columns: (1) Apartment Number that informs about the client's address, (2) Time that informs on when to visit the client, (3) Name that informs on who to visit, and (4) Task Description that informs about the tasks to be performed. The tasks can be viewed as agreed commitments to the clients.

We have identified three communicative situations where the document is used (see Figure 5):

- Planning situation

- Choosing situation

- Resetting situation.

In order to understand each situation we have used a simple diagram labeled the 'Document Activity Diagram.' The diagram presents actors, activities, actions and documents. An example of actor is 'Scheduler;' an example of activity is 'Planning Situation;' an example of action is 'Add;' and an example of a document is 'Morning Tasks.' The aim of the 'Document Activity Diagram' is to describe different activities and how the documents are used in each activity.

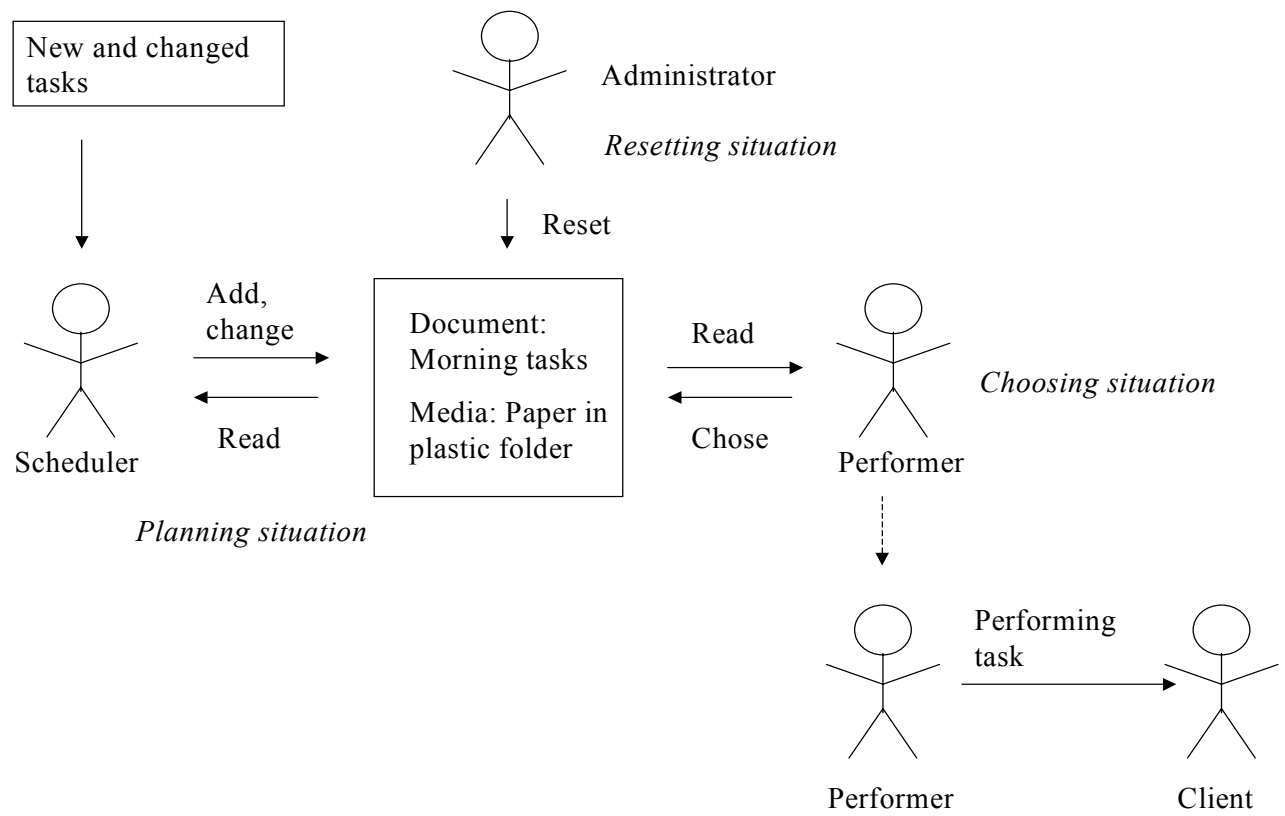

Figure 5: Document Activity Diagram: current work practice communication

In the 'Document Activity Diagram' (see Figure 5), for each situation we have modeled how the sender, the receiver and the actions are related to the document. The diagram also shows how the three situations are related to each other. In the first situation a scheduler plans the tasks. New or changed tasks are added manually (hand-written) to the document. The scheduler informs the performers when there are new or changed tasks by adding them manually to the document. The document is placed in a plastic folder. The procedure for choosing a task is the following: The home care assistant reads the document in order to locate the next appropriate task. Before the home care assistant visits the client, she simply draws a line with a marker pen on the plastic folder over the actual task. The aim of drawing this mark is to inform other assistants that this task has been performed. After the marking, the home care assistant performs the task. When the 
home care assistant returns from the visit, she reads the document in order to locate the next appropriate task. The next day, the administrator rubs out all the markings on the plastic folder. The administrator is 'resetting' the document so it can be re-used.

As Figure 5 shows, there are different communicative situations consisting of different roles that communicate with each other. The document has also different communicative functions depending on the situation. In the 'planning-situation' the communicative function is to inform performers about the tasks that should be carried out. In the 'choosing task-situation' the communicative function is to inform performers of the tasks that have been performed. In the 'resetting-situation' the communicative function is to inform performers about the tasks for the next day.

Based on the problems identified by examining the document 'Morning Tasks,' we have proposed a redesign. Examples of the problems identified were: the information created in the document is not dated (hard to follow-up); the communicator (the scheduler) is not visible; the performer of a task is not visible; changes in the document are written by hand (hard to read, lack of formality, tasks are hard to manage); and tasks that are infrequent and the reasons for not performing a task are omitted.

The original paper-based document is divided into three electronic documents that correspond to the communicative situations depicted in Figure 6:

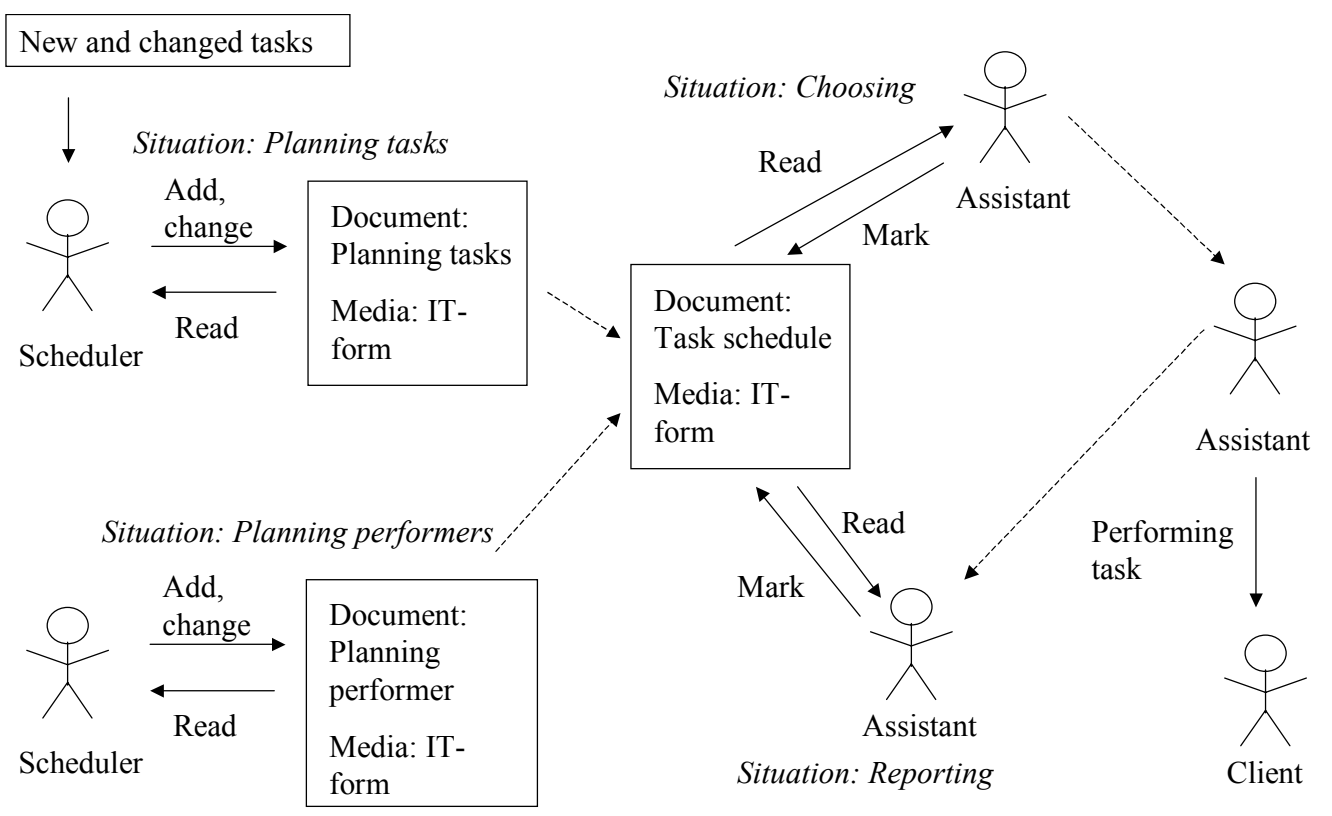

Figure 6: Document Activity Diagram: future work practice communication

- Plan tasks

- Plan performer

- Choose and report task.

We used all the tools for novice user involvement in order to model electronic documents. The tool 'connected to what is known' was implemented through the use of the familiar and existing business document 'Morning Tasks.' The tool 'communication analysis' was used during the analysis of existing and possible future documents. During the development process there was a shift between abstractions and concretions in order to determine the correct analysis. The tools 
'communication analysis' and 'prototyping' have been used when shifting between different abstraction levels.

\section{Findings}

The findings are categorised according to the five tools for novice user involvement: 'Connect to what is known,' 'Shift between the abstract and the concrete,' 'Collect existing documents as a starting point,' 'Communication analyses,' and 'Prototyping.' Each category will be discussed below.

\section{Connect to What is Known}

A high degree of involvement and activity among the users was experienced during the project since they were in a familiar situation. The language and documents involved had been used on a daily basis for several years. This implied that we (the researchers) had to learn the language in the work practice instead of forcing a professional ISD language on the users. Another condition for the users' involvement was that the users themselves had developed the familiar documents. They felt responsible and had knowledge about why the documents were designed in a certain way. Connecting to what is known does not mean that we, as action researchers, have been uncritical. We often questioned the existing documents (both contents and structure) and the concepts and terminology used and the users had to explain and argue why things worked as they did.

We maintain that using the tool 'connecting to what is known' creates a good basis for discussions, questions and analyses. Scholars that subscribe to Participatory Design are arguing that it is important to be able to "make room for the skills, experiences, and interests of workers in system design" since this method can "increase the likelihood that the systems will be useful and well integrated into the work practices of the organization" (Kensing \& Blomberg, 1998, p. 172). The principle of 'connecting to what is known' does not only make room for the novice users' skills and experience but it is also a way of inviting their skills into the design process.

\section{Shift between the Abstract and the Concrete}

The participants (our system users) had little experience of working with computers and they had no prior experience of development projects. These circumstances forced us as designers and action researchers to be very concrete and avoid too much abstract reasoning. In order to develop a well designed IS there is a need for documentation and use of ISD methods. We acknowledged this need and used appropriate IS methods in the process. The methods, however, were not so visible to the users. We have mainly used them as internal quality assurance instruments.

When designing a complex artefact like a computer-based IS, there is of course a need for abstraction and reflection. Abstraction cannot be avoided in the participatory part of the design process. At least partially, the users must be involved in some abstract discussions. There has been a challenge to pursue open reflective discussions in the project sessions together with the novice users. The key to succeeding in this challenging endeavour was to consciously shift between the abstract and the concrete. These findings are in line with Kensing's (2003) proposition that there is a need to shift between the abstract and the concrete. We started with the familiar documents used in the current work practice. These documents were concrete for the users. When discussing different concepts of the documents - sometimes criticizing these concepts in abstract discussions - we always connected these reflections to the well-known documents and the related actions of creating, changing and using these documents.

When we turned to the design phase using prototypes of new IT based documents, this was an even greater challenge. These new screen documents and the accompanying concepts were related explicitly to existing documents and work procedures in order to create new design. The 
design process (which includes abstractions) was taken very carefully and in small steps. Using prototypes resulted in users' comments and critiques. Both positive and negative comments were presented. Sometimes users felt that discussions were too abstract (e.g., when the users were passive and dissociated from the discussion). We tried to be sensitive to such expressions of nonparticipation. When we discovered this low-participatory mode we tried to move back to the concrete, that is, to the familiar documents and different types of action performed within the work practice.

\section{Collect Existing Documents}

Collecting existing documents at a starting point is in line with the tool 'connect to what is known'. First we had to identify the existing documents. The work practice was documentintensive. We identified about 20 different types of documents that were used to transfer knowledge between the nursing assistants. There were both pre-printed and self-made documents (e.g., journals, diaries, note pads, and schedules).

Due to the high amount of documentation we needed to prioritize the documents to begin with. We decided to start with the document labeled 'Carrying out Tasks' both because this was the core task and the problem domain this document represented was in line with the project goal.

The existing documents were identified through consulting the managers and the nursing assistants. We tried to follow the procedure for 'carrying out tasks' and we identified several documents that were used - both pre-printed and self-made. We asked questions, such as "What is the basis for doing this activity?" "How is the result from this activity documented?" The collected documents have acted as a basis for conceptual analysis. We discovered that the documents were also used for transferring knowledge between the nursing assistants.

\section{Communication Analysis}

A major part of the analysis stage has been conducted through the dialogue with the users, which was driven by questions aimed at understanding, reconstruction, analysis and development of a work practice supported by an IS. For each document we asked a battery of questions as follows:

- Why is this document used? This question aimed at understanding the purpose of the document and the contribution of the identified activities to the work practice as a whole.

- How is this document used? The purpose of this question was to identify what information was needed while using the document.

- When is this documents used? This question was asked in order to identify adjacent activities and to identify the document as part of a work process.

- What is the meaning of this concept as part of the document? We used this question in order to understand the concepts used in the document and to be able to relate different concepts to each other.

- Why is this information represented in this document? How do the receivers act differently when they understand what is communicated? The purpose of these questions was to secure that information needed for action was represented and to avoid unnecessary information.

- What do you need in order to produce this information within a document? This question was after identifying the bases needed for working with the document as well as the output. 
- To whom do you communicate the information? This question aimed to identify the receiver, following activities, and the output.

Using these questions implied that the concepts, their meaning and relationships were reconstructed. The conceptual analysis resulted in new concepts, the refinement of existing concepts and in changed concepts along with identifying both synonymous and homonymous concepts.

In the process of transforming paper documents to electronic format, new headings were created. We identified problems when the users referred to the home care journal, for instance. The name 'Home Care Journal' referred either to a folder with several integral documents or just to the folder itself. In order to gain a unique reference, a new name for the folder was formulated.

Another situation that required the creation of a new concept was when nursing assistants planned their visits to the clients. In the analyses of the planning situation it became obvious that one task consisted of several parts. For example, 'morning task' (see figure 4) could consist of parts such as help with dressing, making the bed, making breakfast, etc. Some parts were to be performed every day and others just on particular days. In other words, different parts of the task had different properties, such as when and how they should be performed. Obviously, there was a need for a corresponding concept to the parts of a task. We chose to introduce the concept 'effort' when referring to parts of a task.

In other cases some concepts have been refined. For example, a planning document on a more detailed level showed which nursing assistants should work with a specific task on a certain day. This current document had no name. The users referred to the document simply as the 'planning document.' Since there are other types of planning documents, personnel planning documents and week planning documents, the naming was not sufficiently exclusive. We suggested referring to this document with 'The Day Planning Document'.

There were synonyms as well. The elderly care directors referred to some documents by using different names than those used by the nursing assistants. For example, the nursing assistants used 'Task Plan' when the directors used a synonym. The municipality administration unit used the 'Clients' for what the nursing assistants called 'Elders'. In order to avoid misunderstandings in the communication the project group had to agree on these various labels.

Several concepts have also been changed. For example, in the work practice language there is a concept of 'alarm number.' The concept was used in several documents. When asked what this concept was used for, it became clear that it was a reference to the client residence address. The alarm number was used to locate the client. Since not all clients have an alarm number and they all have a residence (an address), the natural choice was to use 'address' instead of 'alarm number.'

In conclusion, we claim that using documents as a starting point has resulted in a thorough conceptual analysis with a high degree of user involvement. The work practice vocabulary has been refined by both users and action researchers in order to avoid confusion and establish a sound basis for computerization.

Our experience from using the questions is that they have helped us move the requirement analysis process forward. The questions contributed to both identifying the meaning of concepts and improving conditions for communication. The questions have been a catalyst for collective reflection and improvement of part of the work practice language within the project group.

\section{Prototyping}

We created prototypes for the new computer screen documents because several of the informal paper-based documents were to be substituted by electronic documents. Our experiences from 
prototyping are mainly positive. When we started to design the first prototype the users reacted in a rather passive way. We discovered that users did not recognise common interaction elements, such as lists or combo boxes. We had to explain how the elements worked. This was a minor problem since the users were quick learners and they were soon able to criticise solutions that we had suggested. The users even suggested improvements. During the prototype development period, we viewed the users as co-designers.

A disadvantage in this phase was that it was time-consuming since several prototypes had to be developed before the final ones were accepted. The reason for this was that we were meticulous about designing an easy-to-use IS and tried to avoid as much ambiguity as possible. The number of prototypes also led to a lot of re-programming.

\section{Conclusion}

Several conclusions can be drawn from this study with specific references to how the documentdriven approach affected the work practice and users. It can be concluded that the documentdriven systems development approach has led to improvements in work practice. The approach resulted in improved conditions for communication between the users, in conceptual improvements, and in process improvements. It can also be concluded that the users developed a better understanding of the work practice as a whole as well as a greater awareness of how different activities and documents relate to each other. We believe that our approach has contributed to better conditions for knowledge transfer between the users. For example, the refinement of documents improved accuracy of client information and access to it. This is one of the most important conditions for reaching the goal of individualising elderly care services.

Five tools for novice user involvement have guided this approach. The relation between the tools for novice user involvement is depicted in Figure 7.

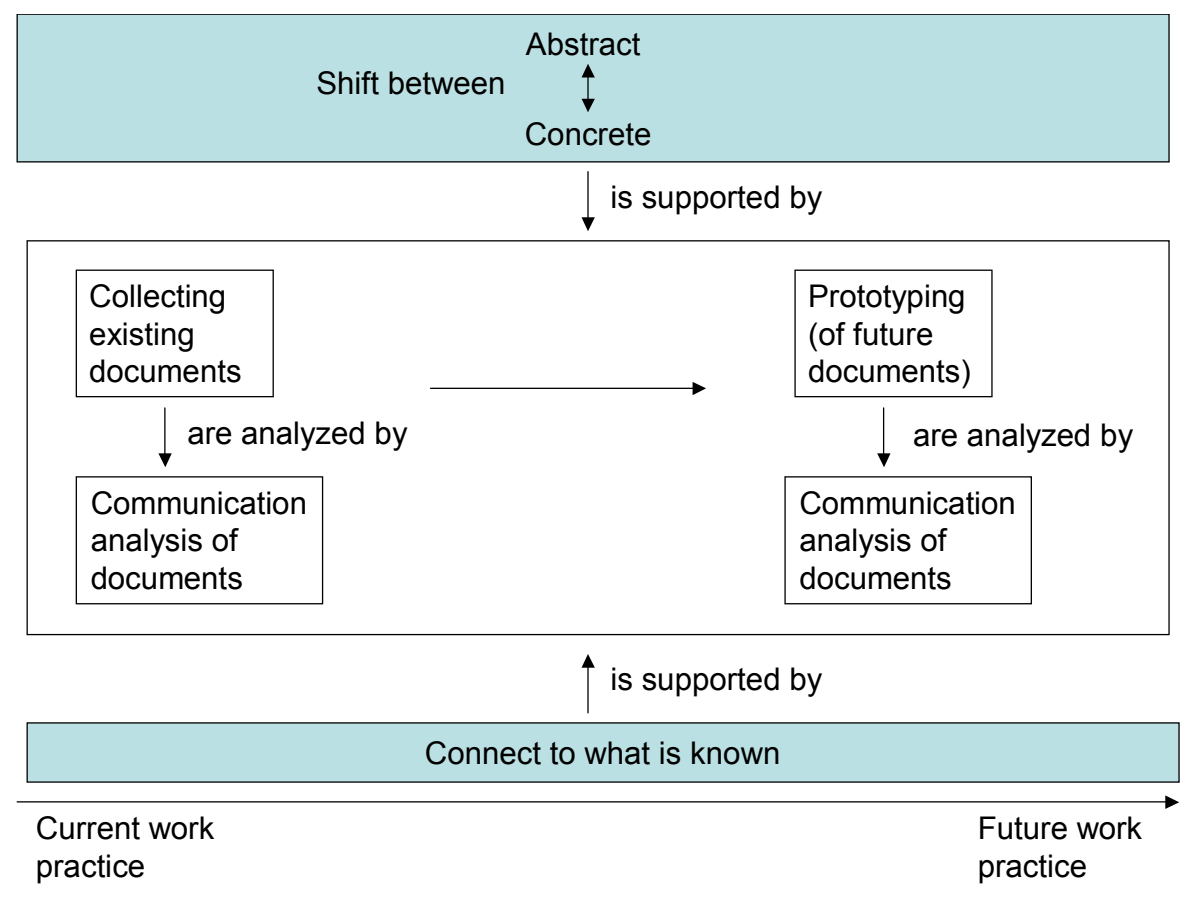

Figure 7: Relationships between the Tools 
At the bottom of Figure 7, there is a time line that describes the evolution from a current work practice situation to a future one. There is a movement from current work practice to future practice. The tool 'collecting existing documents' is in line with 'what is known and familiar.' Both existing documents and future documents are analysed by the tool 'communication analysis.' This tool is therefore generic since it can be used in different situations. The two pillars 'connect to what is known' and 'shift between abstractions and concretions' are present during the whole development process.

We have been careful when changing the meaning of existing concepts or proposing new improved documents. Transparency in the changing process has been an important criterion to anchor new proposals. We believe that the principles 'connect to what is known' and 'shift between the abstract and concrete' have contributed to the communication quality between the system developers (the researchers) and the users. Using the latter of the two principles means that the professional requirement analysts should be aware of when to make abstractions and when there is a need to concretise. Using existing documents as a starting point signifies beginning with what is known.

Our experience from this is that users participated in the analysis and design work in a natural way. In a follow-up interview (made by another inquirer) one of the users was asked the following question: "Were there any difficulties in communicating and did you experience any cultural problems between you and the researchers?" The user answered: "We had to explain quite a lot, but it was OK. Often we had to explain things we considered obvious. It was very fruitful to analyse the work practice and the routines from scratch."

This approach should be considered as a type of participatory design (e.g., Ehn, 1993; Greenbaum, 1993; Kensing, 2003). Participatory design means that people destined to use the system play a critical role in designing it. Easy-to-use IS does not just happen. It requires focusing on the system's potential users from the very beginning. Our users participated as full project members for the duration of the project. They played an active role in order to be sure that they would be satisfied with the final design. We can conclude that using familiar work practice documents rather than more abstract object-oriented models as instruments for communication contributed to high activity among the project members. Users participated as active developers rather than passive deliverers of system requirements. They were co-designers.

Benefits from this participatory design seem to correspond to what has been reported elsewhere "improved communication, lessened resistance to new systems, decreased implementation time, and increased productivity" (Hirschheim, 1985, p. 298). However, it does not suffice that users just participate in design work. As Markus and Mao (2004) put it: "empirical IS participation research, however, exhibits the understanding that users can participate in quite different ways" (p. 531). Therefore, the way the design work is accomplished is crucial. Analysis of our videotapes revealed when the users were active and influential. The design considerations must be intelligible and transparent to the novice users; otherwise, users can become passive and uninvolved. When the design is focused on things that are familiar or at least made familiar to the users, they become actively involved in the design process. The document-driven approach seems to be one way to encourage participatory design.

Document-driven systems development also emphasises the communicative character of information systems. Documents are seen as communication instruments and as such they are also the carriers of work practice language. This means that information systems are not only technical instruments but also the means of enhancing communication in work practices (Goldkuhl \& Lyytinen, 1982; Winograd \& Flores, 1986). Requirements analysis is thus not just a technical change process: introducing computer-based ISes implies changing ways and patterns of communication in the work practice. Changing communication between people means social changes. It 
is crucial to study as part of the ISD process the bases and reasons for such communication changes. This implies the need to study documents in current uses and documents in proposed future uses. Document-driven development makes the ISD process a socio-technical change process. A focus on documents, as key instruments for communication, reveals the social character of work communication and information systems. It also makes the ISD process familiar to users and thus easier to get involved, both emotionally and cognitively.

We do not suggest that a document-driven requirements analysis approach should always be used. Rather, we posit that one should consider the type of work practice and the previous knowledge of the project members, and that a choice of the approach should be made according to these considerations. We believe that different standard approaches are often used without reflection on the development context.

Our conclusions are based on one case study. Despite this, we think that it is possible to make some generalisations. We think that our approach should be considered in every context where there are novice users. Furthermore, we think that the communication analysis is not restricted by context. It can, as a whole or in part, be used in most requirements analysis situations.

We are not claiming that we have developed a new ISD method. Rather, we have constructed a document driven approach consisting of a set of tools for requirement analysis that can be used as a complement to existing ISD methods. Our approach can be used when the goal is to involve novice users in development projects.

\section{References}

Baskerville, R., \& Myers, M. (2004). Special issue on action research in information systems: making IS research relevant to practice - foreword. MIS Quarterly, 28 (3), 329-333.

Baskerville, R., \& Wood-Harper, T. (1996). A critical look on action research as a method for information systems research. Journal of Information Technology, 11, 235-246.

Carlshamre, P. (1994). A collaborative approach to usability engineering, Licentiate thesis. Department of Computer and Information Science, Linköping University, Sweden.

Cronholm, S., \& Goldkuhl, G. (2004). Conceptualising participatory action research - Three different practices. Electronic Journal of Business Research Methods, 2 (2), 47-58.

Cronholm, S., \& Goldkuhl, G. (2005). Communication analysis as perspective and method for requirements engineering. In J. L. Maté \& A. Silva (Eds.), Requirements engineering for sociotechnical systems. Idea Group.

Cunha, P., \& Figueiredo, A. (2002). Action-research and critical rationalism: A virtuous marriage. In Proceedings of the European Conference on Information Systems. Gdansk, Poland.

Ehn, P. (1993). Scandinavian design: On participation and skill. In Schuler \& Namioka (Eds.), Participatory Design. Hillsdale, New Jersey: Lawrence Erlbaum.

Goldkuhl, G., \& Lyytinen, K. (1982). A language action view of information systems. In Ginzberg \& Ross, (Eds.), The Proceedings of the 3rd International Conference on Information Systems. Ann Arbor.

Goldkuhl, G., \& Röstlinger, A. (2002). The practices of knowledge - Investigating functions and sources. In The Proceedings of the 3rd European Conference on Knowledge Management (3ECKM). Dublin.

Greenbaum, J. (1993). A design of one's own: Towards participatory design. In Schuler \& Namioka (Eds.), Participatory design. Hillsdale, New Jersey: Lawrence Erlbaum.

Greenbaum, J., \& Kyng, M. (1991). Design at work: Cooperative design of computer systems. Hillsdale: Lawrence Erlbaum.

Gummeson, E. (1988). Qualitative methods in management research. Bromley, UK: Chartwell-Bratt. 


\section{Document-Driven Requirements Analysis}

Habermas, J. (1984). The theory of communicative action 1. Reason and the rationalization of society. Cambridge: Polity Press.

Hammer, M., \& Champy, J. (1993). Reengineering the corporation. A manifesto for business revolution. London: Nicholas Brealey.

Hirschheim, R (1985). User experience with and assessment of participative systems design. MIS Quarterly, 9 (4), 295-304.

Hägerfors, A. (1994). Co-learning in participative systems design, $\mathrm{PhD}$ thesis. Lund University, Sweden.

Introna, L. D., \& Whitley, E, A. (1997). Against method-ism. Information Technology \& People, 10 (1), $31-45$.

Jayaratna, N. (1994). Understanding and evaluating methodologies. London: McGraw-Hill.

Kemmis, S., \& McTaggart, R. (2000). Participatory action research. In N. Denzin \& Y. Lincoln (Eds.), Handbook of qualitative research (pp. 567-606). Thousand Oaks, CA: Sage.

Kensing, F. (2003). Methods and practices in participatory design. Copenhagen: ITU Press.

Kensing, F., \& Blomberg, J. (1998). Participatory design: Issues and concerns. Computer Supported Cooperative Work, 7, 167-185.

Kling, R. (1977). The organizational context of user-centered software designs. MIS Quarterly, 1 (4), 4152.

Kruchten, P. (1999). The rational unified process: An introduction. Reading, MA: Addison Wesley.

Kvale, S. (1989). Issues of validity in qualitative research. Lund, Sweden: Studentlitteratur.

Löwgren, J. (1993). Human-computer interaction - What every system developer should know. Lund, Sweden: Studentlitteratur.

McKay, J., \& Marshall, P. (2001). The dual imperatives of action research. Information Technology \& People, 14 (1), 45-59.

Markus, L., \& Mao, J-Y. (2004). Participation in development and implementation - Updating an old, tired concept for today's IS. Journal of the Association for Information Systems, 5 (11-12), 514-544.

Monk, A., Wright, P., Haber, J., \& Davenport, L. (1993). Improving your human-computer interface. NewYork: Prentice Hall.

Mumford, E., \& Henshall, D. (1983). Designing participatively. A participative approach to computer systems design. Manchester Business School.

Newman, M., \& Robey, D. (1992). A social process model of user - analyst relationships. MIS Quarterly, $16(2), 249-266$.

Nielsen, J. (1993). Usability engineering. San Diego, California: Academic Press.

Searle, J. R. (1969). Speech acts: An essay in the philosophy of language. London: Cambridge University Press.

Strauss, A., \& Corbin, J. (1998). Basics of qualitative research. Techniques and procedures for developing grounded theory. Beverly Hills, CA: Sage.

Urquhart, C. (1998). Analysts and clients in conversation: Cases in early requirements gathering. In The Proceedings of the 19th International Conference on Information Systems.

Vonk, R. (1990). Prototyping. Cliffs, NJ: Prentice Hall.

Winograd, T., \& Flores, F. (1986). Understanding computers and cognition: A new foundation for design. Norwood: Ablex. 


\section{Biographies}

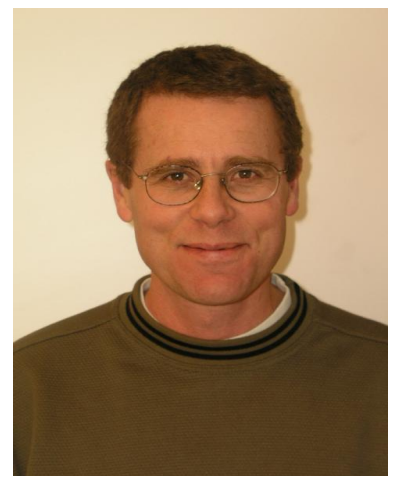

Stefan Cronholm, Associate Professor of Information Systems Development at Linköping University. Stefan Cronholm is the co-director of the Swedish research network VITS, consisting of nearly 40 researchers at six Swedish universities. His areas of interests are information systems evaluation, requirements engineering, communication perspective, and interpretive and qualitative research methods. He is currently developing a theory of evaluation of information systems. His recent works include an analysis of Grounded Theory in use and a contribution to the development of Multi-Grounded Theory (a combination of induction and deduction). (Web site: www.ida.liu.se/ stecr)

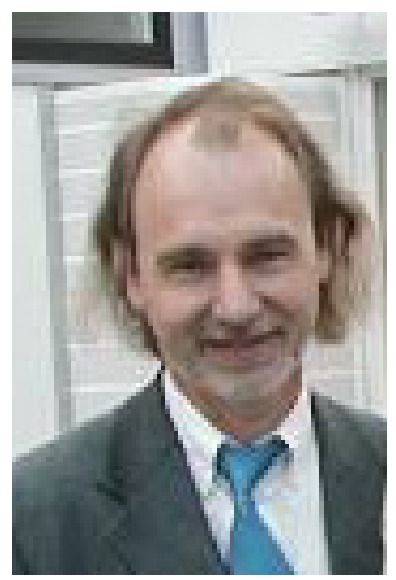

Göran Goldkuhl, Professor of Information Systems Development at Linköping University and Professor of Informatics at Jönköping International Business School. He obtained his Doctoral Degree at Stockholm University in 1980. He is the director of the Swedish research network VITS, consisting of nearly 40 researchers at six Swedish universities. He is currently developing a family of theories that are founded on socio-instrumental pragmatism: Workpractice Theory, Business Action Theory, and Information Systems Actability Theory. $\mathrm{He}$ has a great interest in interpretive and qualitative research methods and he has contributed to the development of Multi-Grounded Theory (a modified version of Grounded Theory). He is active in international communities of researchers interested in the language action perspective and organisational semiotics. (Web site: www.ida.liu.se/ gorgo/ggeng.html) 